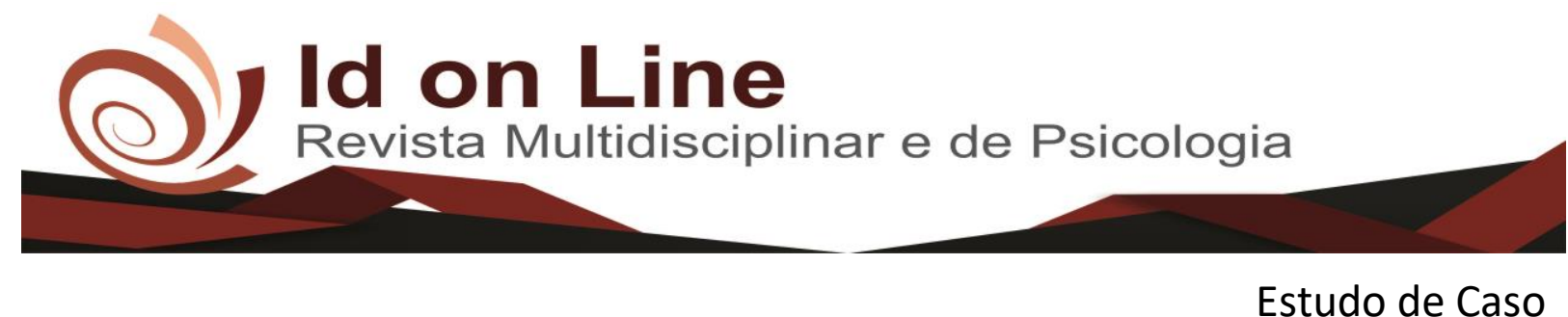

\title{
A Prática Pedagógica no Ambiente Hospitalar: Um Estudo de Caso
}

\author{
Cícera Rayanne Matias Souza ${ }^{1}$; Pedro Fernando dos Santos ${ }^{2}$
}

\begin{abstract}
Resumo: O objetivo deste artigo foi identificar as facilidades e as dificuldades da prática pedagógica docente com crianças em tratamento hospitalar. Houve entrevistas com seis docentes e foram definidas duas categorias. Uma verificou que os conteúdos e objetivos educacionais da escolarização em ambiente hospitalar aproximam-se dos da escola regular, com adequações, devido às condições físicas e emocionais desses alunos. Outra mostrou que as dificuldades são em relação à leitura, memorização, concentração, avaliação, falta de material e espaço físico, enquanto que união e cooperativismo entre docentes, crianças e família são as facilidades. Entendemos como grande desafio a preparação (formação) específica e direcionada dos pedagogos, sobretudo no âmbito do curso de licenciatura em pedagogia, uma vez que fora percebida no decorrer da pesquisa a necessidade de novos conhecimentos e práticas que sirvam de subsídios ao professor. Com este intuito, realizamos pesquisa bibliográfica e de campo, com profissionais da área da saúde e educação, afim de entendermos um pouco sobre o processo educacional existente no âmbito dos hospitais, trazendo ainda, a necessidade de educação hospitalar na cidade de Penaforte-CE. Para que a pesquisa de campo fosse realizada com êxito, tomamos a Teoria de Foucalt (1979) e de Matos e Mugiati (2008), como aporte teórico. Assim, concluímos que essa prática é complexa e há necessidade de novas pesquisas para subsidiar os desafios desse ambiente.
\end{abstract}

Palavras-chave: Educação para todos, Pedagogia Hospitalar, O perfil do pedagogo hospitalar.

\section{The Pedagogical Practice in the Hospital Environment: A Case Study}

\begin{abstract}
The purpose of this article was to identify the facilities and difficulties of teaching pedagogical practice with children in hospital treatment. There were interviews with six teachers and two categories were defined. One verified that the contents and educational objectives of schooling in a hospital environment are close to those of the regular school, with adjustments due to the physical and emotional conditions of these students. Another showed that difficulties are related to reading, memorization, concentration, evaluation, lack of material and physical space, while union and cooperativism among teachers, children and family are the facilities. We understand the specific and targeted preparation (training) of pedagogues as a great challenge, especially in the scope of the licenciatura course in pedagogy, once the need for new knowledge and practices that serve as subsidies to the teacher had been perceived during the course of the research. With this in mind, we conducted bibliographical and field research with health and education professionals, in order to understand a little about the educational process existing in the hospitals, and also the need for hospital education in the city of Penaforte, Ceará. In order for the field research to be carried out successfully, we take the Theory of Foucalt (1979) and Matos and Mugiati (2008), as a theoretical contribution. Thus, we conclude that this practice is complex and new research is needed to subsidize the challenges of this environment.
\end{abstract}

Keywords: Education for all, Pedagogy Hospital, The profile of the hospital pedagogue.

\footnotetext{
${ }^{1}$ Faculdade de Ciências Humanas do Sertão Central (FACHUSC). E-mail: g.vieirapm@ @otmail.com;

${ }^{2}$ Faculdade de Ciências Humanas do Sertão Central (FACHUSC). E-mail: pedrinho_quilombola@ hotmail.com;
} 


\section{Introdução}

Todas as crianças têm o direito ao ensino escolar, mesmo quando debilitadas por adoecimento. A criança enferma tem a necessidade de se sentir produtiva, em desenvolvimento e capaz de prosseguir sua etapa de vida educacional, em se falando de escolarização. Faz-se necessário, assim participar de atividades acadêmicas, pois podem significar, para ela, igualdade com outras crianças e a oportunidade de estar incluída no processo de aquisição do conhecimento.

O intuito desta pesquisa parte do pressuposto de que todos tem o direito constitucional à educação. Sendo assim, entende-se o fato de que a validade das políticas públicas referentes ao atendimento oferecido na Classe Hospitalar vêm sendo consolidadas nos últimos anos, devese considerar que, para melhor atingir seus objetivos há a necessidade de promover o trabalho em conjunto da Classe Hospitalar com a escolar de origem, com o propósito de incluir o aluno enfermo.

Ao abordarmos tal problemática, identificamos como eixo estruturador, "o processo de interlocução do atendimento pedagógico hospitalar com a escola no qual o aluno encontra-se devidamente matriculado". Tal iniciativa é justificada pela necessidade de melhoramento deste atendimento, com vistas a atender o direito de acompanhamento de forma plena. Também se investigou em que medida o atendimento em ambiente hospitalar pode facilitar o retorno do aluno enfermo para escola regular sem prejuízo.

Os objetivos específicos perpassam o perceber como ocorre a interlocução da escola regular com o atendimento escolar hospitalar, assim como refletir sobre as possíveis implicações do atendimento no retorno do estudante e por fim compreender as expectativas das partes nesta relação de correlação entre atendimento e aprendizagem.

Para a confirmação das questões levantas foi realizado uma pesquisa de campo com caráter qualitativo, utilizando técnicas de entrevistas e observação. Foi realizado também um levantamento bibliográfico para melhor embasamento teórico visando uma melhor compreensão. 


\section{A Pedagogia Hospitalar como campo de atuação emergente do pedagogo}

A Pedagogia Hospitalar é uma nova vertente da Pedagogia que objetiva o discurso da educação no espaço hospitalar, valorizando e garantindo o direito da criança enferma. Assim, para melhor compreender a Pedagogia Hospitalar e a atuação do pedagogo neste novo campo.

A necessidade de uma educação humanizadora e dinâmica, que veja o aluno (criança) como um ser em total progresso de desenvolvimento é algo que está cada vez mais presente nos hospitais do Brasil. A demanda de profissionais da saúde, que vislumbrem o seu papel para além de técnico de enfermagem, mas como pedagogo hospitalar; sobretudo no âmbito da oferta de serviços no município de Penaforte-CE.

\section{Hospital: lugar de educação e reabilitação da saúde}

Ao nos deleitarmos na história do nascimento do hospital, identificamos que somente no século XVIII o hospital surge como um instrumento terapêutico, por meio de uma nova prática, como uma instituição destinada a curar pessoas. De acordo com Foucault, podemos afirmar o seguinte:

\footnotetext{
O hospital permanece com essas características até o começo do século XVIII e o Hospital geral, lugar de internamento, onde se justapõem e se misturam doentes, loucos, devassos, prostitutas, etc., é ainda, em meados do século XVII, uma espécie de instrumento misto de exclusão, assistência e transformação espiritual, em que a função médica não aparece. (FOUCAULT, 1979. p. 102)
}

O hospital não era concedido como um espaço de cura, essencial para a vida urbana do Ocidente, mas destinado à assistência aos pobres e, secundariamente, à exclusão e separação dos doentes. Portanto, naquela época a figura central do hospital era o pobre e não o doente, muito diferente da concepção que surge posteriormente.

Foucault (1979) aponta, que, somente muito tempo depois, com a chegada do capitalismo, mudou-se a concepção acerca dos hospitais e suas finalidades. Nesta abertura, o hospital era apenas um ambiente de introdução de mecanismos disciplinares que possibilitariam a aplicação de medicamento nos doentes.

Este poder disciplinar, de um modo geral, foi sendo aperfeiçoado, levando em conta teorias e técnicas; mas, não somente nos hospitais, como também nos espaços escolares, que 
eram estereotipados por um poder ditador. Nos hospitais, existem níveis e funções que eram determinados, não por formação específica, mas pela condição de lidar com determinada situação.

Essa discussão real torna-se ainda mais gritante quando o paciente é uma criança, que está em fase primordial do desenvolvimento humano. E que, portanto, necessita de um atendimento acolhedor, que transpareça a sensibilidade da equipe médica e do hospital, minimizando sua dor e seu sofrimento, assim como de sua família.

De acordo com Matos e Mugiatti:

(...) o que mais importa é que a criança ou adolescente hospitalizado venha receber, sempre e com o máximo empenho, o atendimento a que fazem jus, nessa tão importante fase de sua vida, da qual depende a sua futura estrutura, enquanto pessoa e cidadão. (MATOS e MUGIATI, 2008, p. 65).

Dado o fato, é importante entendermos que a criança hospitalizada, mais que o adulto, necessita de atividades que se aproximem de seu cotidiano, e que ela possa ser vista pela equipe médica como um ser humano que carrega uma trajetória de vida com saberes fundamentais e estruturantes enquanto pessoa e cidadão. Desta forma, entendemos que o tratamento para com a criança hospitalizada, necessita de uma ideia mais abrangente de humanismo e prática humanizadora.

A educação no espaço hospitalar tende a humanizar o atendimento de reabilitação da saúde da criança hospitalizada, pois promove uma interação paciente-equipe médica-famíliaprofissionais da educação em que é possível criar um diálogo profissional, interativo e integrador entre os sujeitos contribuindo, no estado social da criança. Essa atuação da educação com a saúde tem favorecido para diminuir o período de internação, garantir os direitos da criança e do adolescente à escolarização e à saúde, e também tem transformado o espaço triste e doloroso do hospital em local de aprendizagem, encantamento e reabilitação da saúde e da educação.

Além disso, a propagada universalização do atendimento escolar deve alcançar as crianças e adolescentes internados nos hospitais, uma vez que são titulares desse direito subjetivo, estando em situação ainda mais grave porque a evasão escolar deu-se por razões de enfermidade.

A propósito, a Lei $\mathrm{n}^{\circ}$ 9.394, de 20 de dezembro de 1996, conhecida como Lei de Diretrizes e Bases da Educação Nacional, no seu Art. 58, §2 $2^{\circ}$, dispõe que o atendimento 
educacional será feito em classes, escolas ou serviços especializados, sempre que, em função das condições específicas dos alunos, não for possível a sua integração nas classes comuns de ensino "regular".

Complementando a norma legal, a Resolução nº 41, de 13 de outubro de 1995, do Conselho Nacional dos Direitos da Criança e do Adolescente, que dispõe sobre "Direitos da criança e adolescente hospitalizados", prevê o direito da criança e do adolescente de e desfrutar de alguma forma de recreação, programa de educação para a saúde, acompanhamento do currículo escolar, durante sua permanência hospitalar.

Além disso, a Resolução no 2, de 11 de fevereiro de 2001, da Câmara de Educação Básica do Conselho Nacional de Educação, que Institui Diretrizes Nacionais para a Educação Especial na Educação Básica, prevê, em seu Art. 13, que os sistemas de ensino, mediante ação integrada com os sistemas de saúde, devem organizar o atendimento educacional especializado a alunos impossibilitados de frequentar as aulas em razão de tratamento de saúde que implique internação hospitalar, atendimento ambulatorial ou permanência prolongada no domicílio.

Segundo a citada Resolução, as classes hospitalares e o atendimento em ambiente domiciliar devem dar continuidade ao processo de desenvolvimento e ao processo de aprendizagem de alunos matriculados em escolas da Educação Básica, contribuindo para seu retorno e reintegração ao grupo escolar, e desenvolver currículo flexibilizado com crianças, jovens e adultos não matriculados no sistema educacional local, facilitando seu posterior acesso à escola regular.

Por fim, é de se mencionar que a Secretaria de Educação Especial do Ministério da Educação divulgou, em dezembro de 2002, o documento "Classe Hospitalar e Atendimento Pedagógico Domiciliar - estratégias e orientações", em que constam dados oficiais sobre as classes hospitalares e os procedimentos de execução das políticas públicas relacionadas a esse tema.

\section{Algumas práticas educativas no ambiente hospitalar}

As práticas educativas desenvolvidas no hospital se efetivam a partir de ações que articulam o brincar e o aprender, mediante situações que instigam o desejo, a motivação, o interesse, a autoestima, a atenção, a inteligência e a criatividade. 
A denominação Pedagogia Hospitalar deve-se ao fato da necessidade da "existência de uma prática e uma técnica pedagógica nos hospitais, um saber voltado para a criança num contexto hospitalar envolvido no processo ensino-aprendizagem, e por assim ser, instaurou-se como um corpo de conhecimentos a ser estudado" (MATOS; MUGIATTI, 2008, p. 85).

As autoras evidenciam a necessidade de melhor preparação das unidades hospitalares para o trabalho com as crianças. Enfatizam ainda, um espaço hospitalar que contemple momentos de ensino-aprendizagem, tendo em vista que a criança enferma estaria afastada de suas atividades escolares.

Ainda segundo as autoras, a Pedagogia Hospitalar busca a transformar situações e atitudes junto ao enfermo, as quais não podem ser confundidas com o atendimento à sua enfermidade, além disso, deve haver cuidado no desenvolvimento das atividades para que não interfiram no processo terapêutico da equipe médica (MATOS; MUGIATTI, 2008, p. 85).

De acordo com o Conselho Nacional dos Direitos da Criança e do Adolescente (CNDCA), que objetivam relevância pela Lei No 11.104 de 2005, pode-se dizer que a Pedagogia Hospitalar divide-se basicamente em duas modalidades: Classe Hospitalar, que se refere à escola no ambiente hospitalar na circunstância de internação temporária ou permanente; Brinquedoteca e Recreação Hospitalar, que se refere ao direito que a criança tem de brincar, atividade importante para o seu desenvolvimento.

\section{A Brinquedoteca como espaço de aprendizagem lúdica}

Tomaremos como base para esta discussão, o entendimento do que pode ser considerado Brinquedoteca. Entende-se Por Brinquedoteca Hospitalar um espaço no hospital, provido de brinquedos e jogos educativos, destinados a estimular as crianças, os adolescentes e seus acompanhantes a brincarem no sentido mais amplo possível. A Brinquedoteca deve promover o brincar para as crianças hospitalizadas, nos seus leitos ou em um espaço físico especialmente destinado às atividades, permitindo, assim, que a criança exercite os aspectos sensoriais, motores, perceptivos, afetivos, volitivos e sociais um lugar em que o ato de brincar será visto como possibilidade de desenvolvimento de habilidades necessárias e precisas.

Compreendendo a importância da Brinquedoteca no desenvolvimento pleno da criança que brinca através do brincar, com a aprovação da Lei Federal nº 11.104/05, esse espaço tornou- 
se obrigatório em todos os hospitais que atendem crianças, sobretudo, nas grandes metrópoles do país.

Para Viegas (2008),

\begin{abstract}
a Brinquedoteca faz às crianças nascerem novamente, lhes dando alegria ao brincar com objetos que estimulam sua fantasia, fazendo-as descobrirem amigos e um lugar cheio de histórias, músicas, desenhos e teatro, que lhe possibilitam a viagem imaginária em mundos antes desconhecidos. (VIEGAS. 2008, p. 34)
\end{abstract}

O autor mostra que a Brinquedoteca, mesmo para quem não pode locomover-se no hospital, tem grande importância no desenvolvimento, retomando uma parte de sua vida cotidiana, já que os brinquedos podem e devem "integra-se" aos leitos. Obviamente, cabe registrar, sempre mantendo o cuidado com a higienização dos objetos (brinquedos) para não provocarem infecção hospitalar.

\title{
Formação e perfil do pedagogo que atua no hospital
}

Para que esse atendimento especializado e didático possa existir e ser desenvolvido com qualidade e humanização, faz-se evidente a necessidade de profissionais qualificados e bem preparados para lidar com espaço hospitalar, unindo saúde e educação.

Desta forma, o profissional, no caso o pedagogo, precisa de uma formação para tal atuação, formação esta que supere a limitação corpo e mente. Por tais razões, a formação de pedagogos é uma questão muito polêmica no campo da educação que vem sendo discutida desde a antiguidade. Quando se pensa, por exemplo no papel real do pedagogo no âmbito hospitalar.

Para a Pedagogia Hospitalar que tem como público-alvo crianças com necessidades especiais de aprendizagem, por se encontrarem hospitalizadas, a LDB, no Artigo 59, alerta que o professor tenha especialização adequada para que possa desenvolver um atendimento especializado. Isso mostra que sua capacitação para atuar nesse campo dependeria de uma especialização após curso de graduação em Pedagogia, o que se concretiza quando analisamos a quantidade de pedagogos que buscam aperfeiçoamento na área da saúde.

Para Matos e Mugiatti (2008, p. 74) "a ação do pedagogo não deve perder de vista o alvo do seu trabalho - o ser humano - que no momento necessita de ajuda, para livrar-se de seu 
estado físico e psicológico acarretado pela doença ou hospitalização”. (MATOS e MAGIATTI. 2008, p. 74)

\section{Metodologia}

Este trabalho foi realizado com base em uma pesquisa de campo; com intuito de validar a problemática norteadora deste estudo de caso, a metodologia utilizada foi a do tipo qualitativo. Para conceituar a pesquisa qualitativa foi utilizado a definição de Leininger (1985), que tem como objetivo principal documentar e interpretar todos os aspectos que estão sendo estudados em um determinado contexto, sob o ponto de vista dos indivíduos envolvidos. Assim, a identificação, estudo, análise objetiva e subjetiva dos dados, de modo a conhecer a totalidade do espaço estudado através, não apenas da perspectiva do pesquisador, mas dos informantes enquanto co-participantes das informações adquiridas e, portanto, co-autores dos conhecimentos produzidos.

Essa investigação utilizou-se de pesquisa exploratório-descritiva, com o intuito de entender a realidade de forma a ultrapassar os fenômenos percebidos pelos sentidos, trazendo para a análise o subjetivo e o objetivo, os atores sociais e o meio em que estão inseridos. Todo processo de pesquisa investigativa fundamenta-se em realizar um relato partindo da interpretação que o investigador faz de determinadas situações. Avaliar as compreensões do grupo entrevistado para ordená-los em âmbitos e níveis de compreensão, faz-se necessário um exercício de interpretação dos significados de suas compreensões, tomando como base o aporte teórico já citado anteriormente.

Para aprofundamento dessa pesquisa escolhemos o estudo de caso que segundo Bruyne (2001), denomina-se como uma ação de características particular. O ato de generalizar as informações coletas com essa pesquisa tem caráter limitado, sendo que suas conclusões não são aplicadas em casos semelhantes. Esse processo ocorre através de fontes distintas, diferentes em cada caso, ressaltando, de acordo com o autor, que em alguns pontos é possível realizar o ato de generalizações "de forma transitória até novas informações". Os resultados obtidos neste estudo possibilitaram compreender, através de uma amostra, a dinâmica da relação de interlocução da Classe Hospitalar com a escola regular de origem pública. 
A entrevista foi utilizada como um instrumento de coleta de informações, com o intuito de levantar dados que fornecessem subsídios para diagnósticos, análises, pesquisas, ou mesmo com a finalidade de discutir e buscar soluções para alguma problemática levantada.

O atendimento educacional oferecido na Classe é multisseriada e direcionado para cada educando de forma individual, visando assim atender suas disponibilidades e condições físicas/psicológicas. A intenção desse estudo neste pressuposto é através da "escuta sensível" ouvir e observar os agentes que fazem parte deste processo educacional.

Os sujeitos desta pesquisa foram as docentes, discentes e familiares que compõem o contexto observado, de modo a possibilitar uma análise das práticas da correlação existente entre a Classe e a escola e como essa ação influencia no processo de ensino-aprendizagem do educando hospitalizado.

Ressalta-se que em todas as análises deste estudo não haverá intenção de avaliar com o objetivo de classificar e medir competências. Nesta pesquisa, as compreensões dos entrevistados têm o valor de servir de base para elaborar um modelo para âmbito de compressão/interpretação dentro da investigação aqui proposta, tendo o mesmo valor das teorias que sustentam esse trabalho.

\section{Resultados e Discussão}

A observação foi realizada de forma direta e participante, com o objetivo de obter uma avaliação do comportamento dos alunos em seu contexto situacional, com base em uma descrição sistemática do contexto pesquisado e após a observação efetuou-se o registro.

Foram analisados os dados coletados a fim de se efetuar a correlação com o referencial teórico pesquisado. Nesse aspecto, todas as informações foram de grande significado e valor para o procedimento da análise, possibilitando assim estabelecer uma relação de igualdade com cada pessoa que colaborou. Ao fugir dos percursos, das convenções, foram fornecidos parâmetros para responder as indagações norteadoras desta pesquisa.

O processo de análise dos dados da pesquisa utilizado foi a análise de conteúdo coletado, referenciais bibliográficos e observação. Conforme Bardin, (1977) a análise de conteúdo “[...] é um conjunto de técnicas de análise de comunicação que contém informação sobre o comportamento humano atestado por uma fonte documental”. 
O acompanhamento escolar realizado no âmbito hospitalar tem por objetivo vincular o aluno até a escola, assim garantindo um processo escolar pleno, possibilitando o retorno à vida cotidiana sem grandes prejuízos. A maioria das escolas realiza com a carga horária uma relação de parceria, enviando conteúdos e atividades de acordo com o ano escolar do aluno hospitalizado. Esses conteúdos em posse da professora responsável pelo atendimento hospitalar sofrem alterações curriculares necessárias para o melhor aproveitamento.

A docente fica com a responsabilidade de encaminhar os trabalhos realizados no período da internação para a escola de origem da criança e também são enviados os relatórios sobre o rendimento do aluno. A ação pedagógica deve contribuir para que os alunos/paciente hospitalizados consigam dar continuidade ao desenvolvimento das aprendizagens. O pedagogo hospitalar de preferência deve manter a qualidade do vínculo com o conhecimento escolar e não rompê-lo devido à distância física existente entre o aluno enfermo e a escola. Através da pesquisa foi possível constatar que as escolas auxiliaram como possível todos os aspectos com o objetivo de alcançar o êxito no trabalho educacional realizado dentro do espaço hospitalar. As professoras do ensino regular se mostraram interessadas e preocupadas para que não ocorresse a ruptura do processo ensino-aprendizagem. De acordo com Ortiz e Freitas (2001, p. 70) o retorno à escola torna-se "[...] uma ação educacional compatível com o entorno problematizador, para que o paciente-aluno, durante tratamento médico ou após o seu término, não seja absorvido em outra situação de conflito, que é o despreparo para a vida escolar".

Segundo a Professora P1, o retorno da aluna para escola foi repleto de interesse, seu progresso na turma e seu relacionamento afetivo com os colegas tornaram-se mais comparativo e eficaz. Além da continuidade de sua escolaridade, as atividades contribuíram para a socialização entre a classe escolar e o aluno hospitalizado. Princípio contido no PCN: "A escola precisa estar em consonância com as demandas atuais da sociedade, é necessário que trate de questões que interferem na vida dos alunos e com as quais se vêem confrontados no seu dia adia. (PCNs.1997, p.64)".

Fica evidente que o processo de reinserção escolar de crianças ao receber alta médica não é tarefa fácil. O reingresso escolar não é uma ação simples na vida de uma criança que enfrentou o evento de adoecimento e hospitalização. A criança quando retorna ao seu cotidiano se vê diante de um novo desafio a superar, o retorno à sala de aula, e é comum às famílias assumirem uma postura insegura e receosa. Surgem assim, muitas expectativas acerca dos traumas vividos durante a hospitalização, ressaltando o retorno da sensação de desajustes e de 
necessidade de proteção. Segundo o relato das mães observadas, há uma expectativa quanto ao rendimento escolar de seus filhos quando retornam para escola regular.

Entende-se assim, a precariedade na divulgação de informações sobre o trabalho pedagógico-educacional oferecido pelas Classe Hospitalares no Distrito Federal.

O professor realiza o elo na relação entre a criança e o ambiente hospitalar, entre a criança e a família, e entre a criança/adolescente e a escola regular, possibilitando a interação entre essas três instituições, e com isso viabilizando a adaptação da criança/adolescente às mudanças no seu cotidiano e minimizando os possíveis prejuízos.

Diante dos argumentos apresentados, torna-se evidente a importância da relação de diálogo entre a escola regular, a Classe Hospitalar e o educando. É fundamental desenvolver estratégias que atendam às necessidades das crianças/adolescentes hospitalizados que contribuam para que este momento seja superado com êxito.

\section{Conclusões}

A voz das professoras a respeito das experiências vividas na prática pedagógica no ambiente hospitalar demonstrou que há mais dificuldades do que facilidades, e que sanar novos desafios será possível a partir dos dados obtidos. Ficou constatada ainda a necessidade de que outros estudos relativos ao assunto sejam realizados e difundidos, para nortear as propostas pedagógicas nas escolas hospitalares, proporcionando ao docente mais adequadas condições de compreender e avaliar o contexto desse espaço.

O estudo mostrou que é frequente haver, por parte da escola regular, um acompanhamento, principalmente nos casos de doenças crônicas, em que acriança ou adolescente precisam voltar seguidamente ao hospital. Nesse sentido, é imprescindível que os profissionais da educação estejam cientes dos acontecimentos da vida do aluno.

Por meio desta pesquisa foi também possível perceber a importância da interlocução da escola com a Classe, pois essa troca possibilita uma continuidade plena do processo educacional do educando e assim favorecendo seu retorno sem grandes prejuízos para a escola de origem ao fim da internação.

Acredita-se que essa pesquisa irá contribuir para o desbravar de novos horizontes educacionais a serem investigados oportunamente.Com efeito, a troca e a construção coletiva do conhecimento, facilitadas por um atendimento pedagógico pautado nas potencialidades 
individuais da criança enferma, respalda com solidez e eficiência o projeto da Classe Hospitalar e a inclusão da criança enferma na sala de aula regular, enquanto uma das várias alternativas simples e eficazes para não se interromper o processo de escolarização.

Porém, o atendimento pedagógico desenvolvido pela escola hospitalar, ainda é algo que está sendo construído e estruturado, datando, aqui no Brasil, por exemplo, de apenas 60 anos, ensejando a continuação e ampliação de estudo e pesquisa sobre este universo que ora se apresenta aos professores dentre eles, o de música. Ademais, considerando as especificidades próprias do ambiente hospitalar e as condições clínicas do aluno-paciente, surge a necessidade de contínuo aprimoramento profissional para os professores que estarão atuando nesse contexto.

O hospital ora se configura em um lugar de atendimento humanizado, funcionando também como mais um espaço de atuação para o professor. Apesar de recentes, as práticas pedagógicas aí realizadas, além de efetivar a humanização vem proporcionando aprendizagem significativa aos alunos-pacientes. Assim, considerando o estabelecido na legislação, os resultados advindos com esta prática e o grande número de crianças e adolescentes internados precisando de atendimento escolar, a sugestão é ampliar a discussão sobre o assunto, visando à formação continuada do professor que atua e o do que irá atuar no hospital, esperando que haja um aumento na quantidade desses profissionais.

\section{Referências}

, Legislação de educação Inclusiva. Direito á Educação: Necessidades educacionais especiais: Subsídios para a atuação no ministério Publico, 2001. Paulo, 1995.

Estatuto da Criança e do Adolescente. Lei Federal 8.069 de 13 de julho de 1990. São

BARDIN, Laurence. Análise de Conteúdo. Lisboa, Portugal: Edições 70, 1977.

FOUCAULT, Michael. Microfísica do Poder. Organização e tradução de Roberto Machado. Rio de Janeiro: Edições Graal, 1979.

LEININGER, M.M.Métodos de pesquisa qualitativa em enfermagem.Orlando: Grune\&Stratton, Inc, 1985. 
MATOS, Elizete Lúcia Moreira; MUGIATTI, Margarida Maria Teixeira de Freitas. Pedagogia Hospitalar: a humanização integrando educação e saúde. 4. ed. Rio de Janeiro: vozes, 2009. p. $65-85$.

Elizete Lúcia Moreira; MUGIATTI, Margarida Maria Teixeira de Freitas. Pedagogia Hospitalar: a humanização integrando educação e saúde. 4. ed. Rio de Janeiro: vozes, 2009. p. 122.

VIEGAS, D. Brinquedoteca hospitalar: Isto é humanização. $2^{\text {a }}$ Ed. Rio de Janeiro: Wak Ed. 2007.

Como citar este artigo (Formato ABNT):

SOUZA, Cícera Rayanne Matias; SANTOS, Pedro Fernando dos. A Prática Pedagógica no Ambiente Hospitalar: Um Estudo de Caso. Id on Line Rev.Mult. Psic., 2018, vol.12, n.42, Supl. 1, p. 623-635. ISSN: 1981-1179.

Recebido: 12/11/2018;

Aceito: 13/11/2018 